\title{
Concentrated and Fixed-Dose Insulin Formulations Can Improve Outcomes in Patients with Type 2 Diabetes Mellitus
} Jeff Unger*

Department of Family Medicine, University of California Riverside School of Medicine, USA

\begin{abstract}
The risk of developing long-term diabetes mellitus-related complications (retinopathy, nephropathy, neuropathy, cardiovascular disease, and stroke) increases as glycated hemoglobin (A1C) levels exceed 6.5\%. All patients with diabetes should be provided with an individualized target A1C based on factors such as age, duration of disease, risk of hypoglycemia, existing comorbidities, available resources, life expectancy, and cardiovascular risk. A delay of therapeutic intensification of just 2 years from the time of diagnosis can expose a patient to "glycemic burden" and a $61 \%$ increased risk of cardiovascular complications.
\end{abstract}

Keywords: Diabetes mellitus; Nephropathy; Insulins; Glycemic

\section{Introduction}

Recent data from the 2011-2014 National Health and Nutrition Examination Survey (NHANES) indicated that just 51\% of American adults with diabetes achieved A1C levels <7\% [1-5]. Despite the approval and marketing of multiple new agents for diabetes (glucagonlike peptide (GLP)-1 receptor agonists (Ras), SGLT2 inhibitors, longer acting basal insulins, and disposable insulin pumps), improvement of A1C nationwide has declined since NHANES 2007-2010, when 52\% of patients achieved their targeted A1C [5]. Randomized clinical trials, which are conducted with US Food and Drug Administration guidance for a study drug to gain regulatory approval, consistently demonstrate success in achieving A1C levels $<7 \%$ and even $6.5 \%$. However, realworld studies suggest that patient adherence to prescribed medications may mitigate one's ability to achieve glycemic targets [6]. Patients in the real world may be concerned about drug side effects, complexity of treatment regimens, potential weight gain, or risk of hypoglycemia. Television advertisements that mention thyroid cancer, amputation risk, and hypoglycemia may hinder one's desire to initiate a new drug as well.

The former US Surgeon General, C. Everett Koop, once said, "Drugs don't work if patients don't take them [7]." This article will address concentrated insulin and combination fixed-dose insulin + GLP-1 RAs, which reduce the risk of hypoglycemia, weight gain, and cardiovascular disease. The use of these agents within the primary care setting may improve adherence and allow patients to safely and efficiently achieve their prescribed glycemic targets.

\section{Literature Review}

\section{Insulin action, variability, and recommended glycemic targets}

Insulins are formulated to bind to and activate receptors located with target organs (i.e., liver, muscles, kidneys, adipose tissue). The resultant pharmacologic action ultimately lowers plasma glucose levels to the desired range. The fact that not all insulins are created equal allows practitioners to customize their treatment protocols for each patient.

The American Association of Clinical Endocrinologists recommends the use of insulin when the endogenous insulin-secreting capacity of pancreatic beta cells has been exceeded. Insulin should be initiated in any patient with an $\mathrm{AlC} \geq 8.5 \%$ who has symptoms suggestive of chronic hyperglycemia (e.g., thirst, weight loss, blurry vision, distal sensory neuropathy, weight loss, frequent urination). Patients with an A1C level $>9 \%$ should also be considered as candidates for insulin
[8]. Basal insulin reduces hepatic glucose production in the fasting state, whereas rapid-acting insulin preparations are used to minimize postprandial glucose excursions. The American Diabetes Association recommends targeting fasting glucose levels of 70 to $130 \mathrm{mg} / \mathrm{dL}$ and 2-hour post-meal glucose level of $<180 \mathrm{mg} / \mathrm{dL}$ [9].

Early initiation of insulin can prove beneficial for patients with type 2 diabetes. The anti-inflammatory and antioxidant effects (i.e., reduction of oxidative stress) may offer protection against vascular endothelial dysfunction and subsequent vascular disease. Insulin induces endothelial nitric oxide synthase in endothelial cells, resulting in increased production of nitric oxide and the promotion of vascular dilatation [10]. Insulin is thought to preserve $\beta$-cell mass and function in patients with type 2 diabetes. Glycemic burden destroys $\beta$-cells. Reducing hyperglycemia in patients with diabetes can facilitate $\beta$-cell rest, allowing for more efficient and timely production and secretion of endogenous insulin [11].

Although elevated $\mathrm{A} 1 \mathrm{C}$ is a surrogate marker for long-term diabetesrelated complications, glycemic variability (dysglycemia) can induce oxidative stress favoring the induction of complications [12]. Patients who experience dysglycemia become frustrated with their inability to efficiently regulate blood glucose levels. These patients experience wide glycemic swings throughout the day, resulting in hypoglycemia and sustained hyperglycemia. Efficient pharmacotherapy for patients with type 2 diabetes must address both the effects of prolonged exposure to hyperglycemia as well as acute daily excursions of glucose levels. Elevated glucose levels promote the appearance of acute glycated end products, which can increase one's likelihood of developing complications. Glycemic excursions exacerbate the process of oxidative stress, a metabolic state favoring the progression of microvascular and macrovascular complications [13].

*Corresponding author: Jeff Unger, Department of Family Medicine, University of California Riverside School of Medicine, USA; Tel: (951) 255-5575; E-mail: jungermd@aol.com

Received: December 06, 2017; Accepted: January 08, 2018; Published: January 11,2018

Citation: Unger J (2017) Concentrated and Fixed-Dose Insulin Formulations Can Improve Outcomes in Patients with Type 2 Diabetes Mellitus. Diabetes Case Rep 3: 133. doi: 10.4172/2572-5629.1000133

Copyright: (C) 2017 Unger J. This is an open-access article distributed under the terms of the Creative Commons Attribution License, which permits unrestricted use, distribution, and reproduction in any medium, provided the original author and source are credited. 


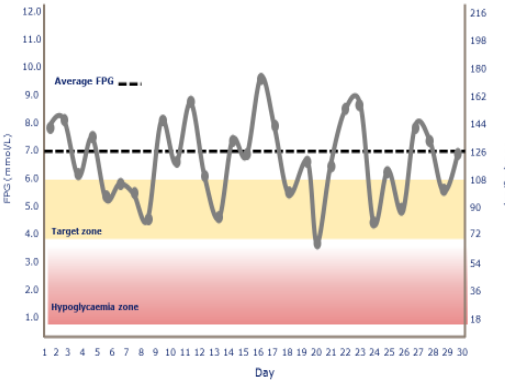

(a)

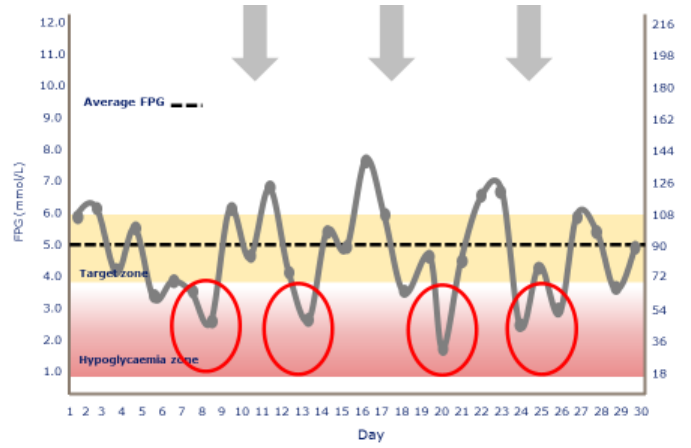

(b)

Figure 1: Glucose variability and the risk of hypoglycemia.

\begin{tabular}{|c|c|}
\hline Insulin & Within-subject variability $^{*}$ \\
\hline NPH & 68 \\
\hline Glargine U-100 & 48 \\
\hline Detemir & 27 \\
\hline (Concentrated) Glargine U-300 & 34.8 \\
\hline Degludec & 20 \\
\hline
\end{tabular}

Table 1: Basal insulin coefficients of variability.

Ideal basal insulins should be simple to initiate and titrate, resulting in minimal glycemic variability, as well as providing prolonged duration of action while reducing one's risk of hypoglycemia and weight gain. In addition, insulins should not increase one's risk of cardiovascular disease, especially in patients who have already experienced a stroke or myocardial infarction. Table 1 provides the coefficients of variability of available basal insulins [14-16]. The lower the variability, the less likelihood of developing treatment-emergent hypoglycemia, as noted in the Figures $1 \mathrm{a}$ and $1 \mathrm{~b}$.

*Percentage within-subject variability based on glucose infusion rates and area under the curve. Patients receive 4 single subcutaneous doses of $0.4 \mathrm{U} / \mathrm{kg}$ under euglycemic glucose clamp conditions on 4 study days. NPH=Neutral Protamine Hagedorn.

A patient is using an insulin with a high coefficient of variability. Glucose levels demonstrate "dysglycemia" (A). Increasing the basal insulin further is likely to increase the risk of hypoglycemia, which will reduce adherence to the prescribed treatment regimen (B). The use of basal insulin formulations with low glycemic variability will allow patients to achieve their fasting blood glucose targets more efficiently, with less fear of hypoglycemia [17].

\section{New insulin formulations}

Advances in basal insulin formulations have provided clinicians and patients with options that provide favorable pharmacokinetic (insulin absorption) and pharmacodynamic (glucose lowering) properties. Newer insulins have flatter, peakless action profiles that demonstrate less variability and a longer duration of action, allowing for flexible dosing. The risk of nocturnal and diurnal hypoglycemia is subsequently reduced. Insulin preparations do not appear to increase cardiovascular risk $[18,19]$. Patients may also safely combine a GLP-1 RA as either a separate injection or as a component of a fixed-ratio drug. The use of fixed-drug combinations may improve adherence and allow patients to achieve their metabolic targets [20].

\section{Glargine U-300}

Glargine U-300 is a long-acting insulin containing 300 units/mL of insulin glargine. As a concentrated insulin, glargine U-300 contains 3 times as much insulin per $\mathrm{mL}$ as glargine $\mathrm{U}-100$, allowing for a lower volume of injected insulin. Glargine U-300 was detectable at 32 hours post-injection with 0.4 units $/ \mathrm{kg}$ dosing compared with 28 hours with glargine U100 dosing [21]. At $0.4 \mathrm{u} / \mathrm{kg}, \mathrm{U}-300$ has $14 \%$ less variability than U-100, allowing clinicians to titrate the insulin to target lower fasting glucose levels without risking hypoglycemia [15].

\section{Degludec U-100 and U-300}

Within the insulin pen, insulin degludec is formulated as "insulin diheximers." Once injected, the diheximers form multiheximer chains within the subcutaneous depot, held together by zinc and phenol. As the zinc dissociates, the multiheximers form insulin monomers, which pass into the capillaries and are carried via albumin to insulin receptors at target organ sites. Degludec U-200 contains as much insulin as degludec U-100 in just one-half the injection volume. The 2 insulins are bioequivalent, and they lower glucose levels at the same rate. Degludec appears to have the lowest coefficient of variability of all insulins, allowing ambitious dosing to targeted fasting glucose levels, with less likelihood of nocturnal and overall hypoglycemia compared with insulin glargine [22]. Due to the prolonged duration of action (42 hours), degludec may be dosed at any time of the day, which may improve adherence for patients who are shift workers, travel frequently, or have difficulty remembering to dose their basal insulin [23].

\section{U-500 regular insulin}

Regular insulin U-500 is structurally identical to human insulin. Because the drug is formulated as 500 units $/ \mathrm{mL}$, this insulin is 5 times as potent as regular insulin U-100 [24]. U-500 is indicated for patients with type 1 or type 2 diabetes, requiring more than 200 units of insulin daily. The concentrated insulin is delivered in a lower injection volume, which improves the drug's absorption from the subcutaneous depot. U-500 has a slower onset of action (60 minutes) compared with rapidacting prandial insulins. The peak onset of action is 2 to 4 hours postinjection, and the duration of action is 4 to 6 hours [16]. U-500 can be dosed as prandial insulin, using a pen injector 30 to 45 minutes prior to eating.

\section{Insulin Lispro U-200}

Prandial insulin lispro U-200 contains 200 units of rapid acting insulin per $\mathrm{mL}$ compared with insulin lispro U-100, which contains 100 units $/ \mathrm{mL}$. Thus, U-200 is twice as concentrated as U-100, allowing patients requiring $>20$ units of insulin per meal to inject less volume [25]. The pharamacokinetic and pharmacodynamic effects of both lispro U-200 and lispro U-100 are equivalent [25]. 
Citation: Unger J (2017) Concentrated and Fixed-Dose Insulin Formulations Can Improve Outcomes in Patients with Type 2 Diabetes Mellitus. Diabetes Case Rep 3: 133. doi: 10.4172/2572-5629.1000133

Page 3 of 4

\begin{tabular}{|c|c|c|}
\hline Condition & Rationale & Product of choice \\
\hline Nocturnal hypoglycemia & $\begin{array}{l}\text { Needs peak-less (flat) basal insulin profile } \\
\text { Insulins with lower glycemic variability will allow safer titration to fasting } \\
\text { glucose levels without risk of hypoglycemia }\end{array}$ & Glargine U-300, Degludec U-100 or U200 \\
\hline $\begin{array}{l}\text { Severe insulin resistance requiring the use of } \\
\qquad>200 \text { units of insulin daily }\end{array}$ & 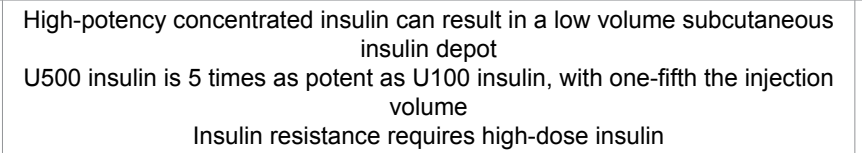 & Regular U500 insulin \\
\hline $\begin{array}{l}\text { Patient requires }>80 \text { units of basal insulin per } \\
\text { injection }\end{array}$ & $\begin{array}{l}\text { Concentrated insulin formulations have been developed to address the need } \\
\text { for higher dose insulin delivery of a single daily injection }\end{array}$ & Degludec U-200, Glargine U-300 \\
\hline $\begin{array}{l}\text { Patient requires flexible daily dosing due to } \\
\text { work schedule or frequent travel }\end{array}$ & $\begin{array}{l}\text { Degludec can be administered daily at any time of day, with injection timing } \\
\text { varied, without compromising glycemic control or safety }\end{array}$ & Insulin degludec U-100 or U-200 \\
\hline Patient requires $>20$ units of prandial insulin & Lowers cost; low-volume insulin reduces the number of pen requirements monthly & Lispro U-200 \\
\hline $\begin{array}{l}\text { Postprandial and fasting glucose coverage is } \\
\text { needed }\end{array}$ & $\begin{array}{l}\text { Fixed-dose combination therapy with insulin + GLP-1 receptor agonist can } \\
\text { reduce total daily dose of insulin, risk of weight gain associated with insulin } \\
\text { use, and provide coverage for postprandial excursions }\end{array}$ & $\begin{array}{l}\text { Insulin degludec + liraglutide }(100 / 3.6) \\
\text { Insulin glargine + lixisenatide }(100 / 33)\end{array}$ \\
\hline
\end{tabular}

Table 2: Rationale for use of concentrated insulins.

\begin{tabular}{|c|c|c|c|}
\hline Metabolic target & Basal insulin & GLP-1 RA & Combination therapy \\
\hline Beta-cell function & $\begin{array}{l}\text { Rests beta cells, relieves } \\
\text { glucotoxicity }\end{array}$ & $\begin{array}{l}\text { Improves beta-cell function } \\
\text { May restore beta-cell mass }\end{array}$ & $\begin{array}{l}\text { Additive improvement in prandial and postprandial glucose levels } \\
\text { with lower total daily dose of insulin required }\end{array}$ \\
\hline Alpha-cell function & Reduces glucagon & Reduces glucagon & $\begin{array}{l}\text { Additive improvement in glucagon secretion results in lower fasting } \\
\text { and postprandial glucose levels } \\
\text { Diabetes is a bi-hormonal disorder; too much glucagon produced by } \\
\text { the alpha cell and too little insulin secreted by the beta cell }\end{array}$ \\
\hline Glucose control & Targets fasting blood glucose & $\begin{array}{l}\text { Targets primarily postprandial } \\
\text { glucose }\end{array}$ & $\begin{array}{l}\text { Lower fasting and postprandial glucose levels } \\
\text { Improved A1C }\end{array}$ \\
\hline Weight & Tends to increase & Tends to decrease & Less weight gain noted with combination \\
\hline Hypoglycemia risk & Increase risk & Lower risk & $\begin{array}{l}\text { Lower risk due to reduced insulin dose requirements when } \\
\text { combined with a GLP-1 RA }\end{array}$ \\
\hline Cardiovascular (CV) risk & $\begin{array}{l}\text { Insulin does NOT increase } \\
\text { cardiovascular risk, nor is the risk } \\
\text { reduced }\end{array}$ & $\begin{array}{l}\text { Liraglutide }{ }^{a} \text { and semaglutide }{ }^{b, c} \\
\text { reduce CV risk. Other GLP-1 RAs } \\
\text { are neutral at reducing risk }\end{array}$ & $\begin{array}{l}\text { Studies have not been performed assessing the CV risk in fixed- } \\
\text { dose combination therapies, only as individual interventions }\end{array}$ \\
\hline
\end{tabular}

Table 3: Combination of basal insulin and GLP-1 receptor agonists.

Table 2 presents concentrated insulin or fixed-insulin combination, which might be appropriate for patients with type 2 diabetes.

\section{Fixed-dose combinations (Basal insulin and GLP-1 receptor agonists)}

The combination of basal insulin analogues with a glucagonlike GLP-1 RA is intriguing. Basal insulin essentially targets hepatic glucose production, which is excessive in patients with type 2 diabetes. However, the use of basal insulin may result in weight gain and/or hypoglycemia, which affects adherence [26]. The GLP-1 RAs typically target postprandial glucose excursions by decreasing the excretion of endogenous glucagon, a counterregulatory hormone, which induces hepatic glucose production [27]. Patients using GLP-1 RAs tend to lose weight. Because this class of drugs is "glucose dependent," the glucoselowering effects in patients with lower blood glucose levels is reduced. Thus, patients tend to experience less hypoglycemia. Liraglutide, a GLP$1 \mathrm{RA}$, has demonstrated a $22 \%$ reduction in cardiovascular mortality [28]. However, extrapolation of cardiovascular outcomes in fixed-dose combinations cannot be inferred without having trials specific to the dual-therapy option [28-30].

Table 3 lists the features of basal insulin plus GLP-1 RAs, which makes their combination therapies attractive in patients with type 2 diabetes.

\section{Discussion}

The treatment of type 2 diabetes is complicated not by only the chronic progressive nature of the disease but the multiple "core" defects that must be addressed. Patients with diabetes experience beta-cell failure, increased insulin resistance due to hepatic glucose production, and a reduced glucose uptake in the muscle and fat cells. The kidneys absorb excessive amounts of glucose in the face of hyperglycemia and even produce glucose in the form of gluconeogenesis. Due to the reduction in circulating insulin, fat cells produce excessive amounts of free fatty acid, which further increases hepatic glucose production. Feelings of satiety are reduced in patients with type 2 diabetes, resulting in overconsumption of nutrients and weight gain. Native GLP-1 (a gut hormone released in response to a carbohydrate load) is either reduced or its action is compromised at the receptor site, resulting in a reduction in prandial insulin production and excess glucagon production from the pancreatic alpha cells. The use of concentrated insulins, as well as new insulins with more favorable pharmacokinetic and pharmacodynamic profiles, may profoundly improve glycemic control in patients with diabetes. Fixed-dose combinations that employ basal insulin plus a GLP-1 RA appear to be a rationale choice for patients who require better postprandial glucose coverage.

\section{Conclusion}

Patients who are nonadherent to a treatment regimen may benefit from concentrated or combination therapies. Adherence is likely to improve fasting and postprandial glucose control, allowing patients to successfully achieve their targeted A1C level and reduce their glycemic burden. Using insulins with less variability and risk of hypoglycemia will also improve adherence. Because $90 \%$ of all patients with diabetes are managed within the primary care setting, the treatment of diabetes must be intensified within our environment. Early and successful treatment of these complex individuals will likely improve long-term outcomes and our patients' quality of life. 
Citation: Unger J (2017) Concentrated and Fixed-Dose Insulin Formulations Can Improve Outcomes in Patients with Type 2 Diabetes Mellitus. Diabetes Case Rep 3: 133. doi: 10.4172/2572-5629.1000133

\section{Acknowledgement}

Author thanks the staff at Vindico Medical Education for their assistance in the preparation of this manuscript.

\section{References}

1. Selvin E, Ning Y, Steffres MW, Bash LD, Klein R, et al. (2011) Glycated hemoglobin and the risk of kidney disease and retinopathy in adults with and without diabetes. Diabetes 60: 298-305.

2. Selvin E, Steffes MW, Zhu H (2010) Glycated hemoglobin, diabetes, and cardiovascular risk in nondiabetic adults. N Engl J Med 362: 800-811.

3. Inzucchi SE, Bergenstal RM, Buse JB (2015) Management of hyperglycemia in type 2 diabetes, 2015: A patient-centered approach. Update to position statement of the American Diabetes Association and the European Association for the Study of Diabetes. Diabetes Care 38: 140-149.

4. Paul SK, Klein K, Thorsted BL (2015) Delay in treatment intensification increases the risks of cardiovascular events in patients with type 2 diabetes. Cardiovasc Diabetol 14: 100

5. Edelman SV, Polonsky WH (2017) Type 2 diabetes in the real world: the elusive nature of glycemic control. Diabetes Care 40: 1425-1432.

6. Rothwell PM (2005) External validity of randomized controlled trials: "to whom do the results of this trial apply?" Lancet 365: 82-93.

7. Lindenfeld J, Jessup M (2017) Drugs don't work in patients who don't take them. C. Everett Koop, MD US Surgeon General, 1985. Eur J Heart Fail 19 1412-1413.

8. Rodbard HW, Jellinger PS, Davidson JA (2009) Statement by an American Association of Clinical Endocrinologists/American College of Endocrinology consensus panel on type 2 diabetes mellitus: An algorithm for glycemic control. Endocr Pract 15: 540-559.

9. American Diabetes Association (2016) Glycemic targets. Diabetes Care 39: S39-S46.

10. Owens DR (2013) Clinical evidence for the earlier initiation of insulin therapy in type 2 diabetes. Diabetes Technol Ther 15: 776-785.

11. Turner RC, McCarthy ST, Holman RR, Harris E (1976) Beta-cell function improved by supplementing basal insulin secretion in mild diabetes. $\mathrm{Br} \mathrm{Med}$ J 1: 1252-1254.

12. Unger $J$ (2008) Reducing oxidative stress in patients with type 2 diabetes mellitus: A primary care call to action. Insulin 3: 176-184.

13. Monnier L, Colette C, Owens DR (2008) Glycemic variability: the third component of the dysglycemia in diabetes. Is it important? How to measure it? J Diabetes Sci Technol 2: 1094-1095.

14. Rossetti PL, Ampudia-Blasco FJ, Ascaso JF (2014) Old and new basal insulin formulations: understanding pharmacodynamics is still relevant in clinical practice. Diabetes Obes Metab 16: 695-706.
15. Becker RH, Nowotny I, Teichert L, Bergmann K, Kapitza C (2015) Low withinand between-day variability in exposure to new insulin glargine $300 \mathrm{U} / \mathrm{ml}$. Diabetes Obes Metab 17: 261-267.

16. Unger J (2012) Insulin initiation and intensification for patients with T2DM. In Diabetes management in primary care. (2nd edn). Philadelphia, PA: Lippincott, Williams and Wilkins, USA. pp. 453-490.

17. Vora J, Heise T (2013) Variability of glucose-lowering effect as a limiting factor in optimizing basal insulin therapy: a review. Diabetes Obes Metab 15: 701 712

18. Gerstein HC, Bosch J (2012) Basal insulin and cardiovascular and other outcomes in dysglycemia. N Engl J Med 367: 319-328.

19. Marso SP, McGuire DK, Zinman B (2017) Efficacy and safety of degludec versus glargine in type 2 diabetes. N Engl J Med 377: 723-732.

20. Ferdinand KC, Senatore FF, Clayton-Jeter H (2017) Improving medication adherence in cardiometabolic disease: practical and regulatory implications. J Am Coll Cardiol 69: 437-451.

21. Becker RH, Dahmen R, Bergmann K, Lehmann A, Jax T, et al. (2015) New insulin glargine 300 Units. $\mathrm{mL}-1$ provides a more even activity profile and prolonged glycemic control at steady state compared with insulin glargine 100 Units. $\mathrm{mL}-1$. Diabetes Care 38: 637-643.

22. Wysham C, Bhargava A, Chaykin L (2017) Effect of insulin degludec vs insulin glargine U100 on hypoglycemia in patients with type 2 diabetes The SWITCH 2 randomized clinical trial. JAMA. 318: 45-56.

23. Meneghini L, Atkin SL, Gough SC (2013) The efficacy and safety of insulin degludec given in variable once-daily dosing intervals compared with insulin glargine and insulin degludec dosed at the same time daily; a 26-week randomized, open-label, parallel-group, treat-to-target trial in individuals with type 2 diabetes. Diabetes Care 36: 858-864

24. https://www.accessdata.fda.gov/drugsatfda docs/label/2016/018780s153lbl. pdf.

25. https://www.accessdata.fda.gov/drugsatfda_docs/label/2017/020563s176lbl. pdf.

26. Pi-Sunyer FX (2009) The impact of weight gain on motivation, compliance, and metabolic control in patients with type 2 diabetes mellitus. Postgrad Med 121 : 94-107.

27. Unger JR, Parkin CG (2011) Glucagon-like peptide-1 (GLP-1) receptor agonists: Differentiating the new medications. Diabetes Therapy 2: 29-39.

28. Marso SP, Daniels GH, Brown-Frandsen K (2016) Liraglutide and cardiovascular outcomes in type 2 diabetes. N Engl J Med 375: 311-322.

29. Marso SP, Bain SC, Consoli A (2016) Semaglutide and cardiovascula outcomes in patients with type 2 diabetes. N Engl J Med 375: 1834-1844.

30. Anderson SL, Trujillo JM (2016) Basal insulin use with GLP-1 receptor agonists Diabetes Spectr. 29: 152-160. 